\title{
AIRBORNE CAMERA SYSTEM FOR REAL-TIME APPLICATIONS - SUPPORT OF A NATIONAL CIVIL PROTECTION EXERCISE
}

\author{
V. Gstaiger ${ }^{\text {a, }}$, H. Römer ${ }^{\text {b }}$, D. Rosenbaum ${ }^{\text {a }}$, F. Henkel ${ }^{\text {b }}$ \\ ${ }^{a}$ German Aerospace Center (DLR), Earth Observation Center, Remote Sensing Technology Institute, Photogrammetry and Image \\ Analysis, Oberpfaffenhofen, 82234 Weßling, Germany - Veronika.Gstaiger@dlr.de; Dominik.Rosenbaum@dlr.de \\ ${ }^{\mathrm{b}}$ German Aerospace Center (DLR), Earth Observation Center, German Remote Sensing Data Center, Geo-Risks and Civil Security,
} Oberpfaffenhofen, 82234 Weßling, Germany-Hannes.Roemer@dlr.de; Fabian.Henkel@dlr.de

Commission VI, WG VI/4

KEY WORDS: Airborne Camera System, Traffic Monitoring, Real-time Situation Assessment, Civil Protection

\begin{abstract}
:
In the VABENE++ project of the German Aerospace Center (DLR), powerful tools are being developed to aid public authorities and organizations with security responsibilities as well as traffic authorities when dealing with disasters and large public events. One focus lies on the acquisition of high resolution aerial imagery, its fully automatic processing, analysis and near real-time provision to decision makers in emergency situations. For this purpose a camera system was developed to be operated from a helicopter with light-weight processing units and microwave link for fast data transfer. In order to meet end-users' requirements DLR works close together with the German Federal Office of Civil Protection and Disaster Assistance (BBK) within this project. One task of BBK is to establish, maintain and train the German Medical Task Force (MTF), which gets deployed nationwide in case of large-scale disasters. In October 2014, several units of the MTF were deployed for the first time in the framework of a national civil protection exercise in Brandenburg. The VABENE++ team joined the exercise and provided near real-time aerial imagery, videos and derived traffic information to support the direction of the MTF and to identify needs for further improvements and developments.

In this contribution the authors introduce the new airborne camera system together with its near real-time processing components and share experiences gained during the national civil protection exercise.
\end{abstract}

\section{INTRODUCTION}

Disaster management during natural disasters or large public events is highly dependent on current and reliable information. In order to gather information necessary for making decisions all possible sources of information have to be used. Information on the transport system is particularly important, since the mobility of the public and relief teams plays a key role for fast and efficient disaster relief. In the project VABENE++ Traffic Management for Large Scale Events and Disasters of the German Aerospace Center (DLR) tools are being developed to provide information from several data sources such as satellite data, aerial imagery and terrestrial information. Aerial images have proved to be particularly well suited for disaster relief applications, since they provide a fast overview of a situation and can be easily understood. In order to provide a comparatively cheap optical sensor compared to commercial aerial camera systems, the 3K camera system was developed (Kurz et al. 2012) and built into the research aircrafts Cessna 208B Grand Caravan and Dornier DO228-212 of DLR. Now, the camera system has been improved and implemented as $4 \mathrm{k}$ camera system on the helicopter BO105 of DLR.

Automatic processing and analysis of the images create additional information, e.g. current traffic data, which can be transmitted via a microwave data link and visualised directly at the coordination offices in near real-time during the disaster. These applications were requested by the BBK to support the national civil protection exercise "Flinker Oktopus", which took place in late October 2014.

\section{VABENE++ PROJECT OBJECTIVES}

The goal of the VABENE++ project is to efficiently manage the required rescue logistics and the nearby traffic flow even under extreme conditions, thereby enabling response teams to rapidly reach the locations where they are needed. Scientists from various DLR institutes collaborate in this research project with the support of DLR's Research Flight Facilities. The Chair of Remote Sensing Technology at Munich Technical University (TU Muenchen) and the Department of Geoinformatics and Remote Sensing at Osnabrueck University also participate in VABENE++.

In order to support situation assessment and rescue logistics, research focuses on monitoring and modelling of traffic, traffic risk assessment, data fusion and management as well as on developing web technologies in a GIS environment. Each of these applications requires detailed and high quality input data from different sources like satellite data, aerial images and ground-based information from terrestrial cameras or other data sources such as induction loops, which can be provided within or are supported by the VABENE++ system. For demonstrations of new technologies the VABENE++ team works close together with civil protection and humanitarian aid agencies. In addition, these events are used to identify further user requirements or suggestions for improvements of the existing tools.

\footnotetext{
* Corresponding author.
} 


\section{4K CAMERA SYSTEM FOR CIVIL PROTECTION SUPPORT}

\subsection{German Medical Task Force}

One of the end-users of VABENE++ is the BBK situated in Bonn, Germany. Being Germany's central organisational element ensuring safety of the population, the BBK has to discharge several tasks. Among others, the work of the Office includes civil protection activities, planning and preparation of measures to provide emergency supplies, emergency planning, planning and preparation of cooperation between the Federation and the Länder with regard to special hazards (coordination of crisis management) and training in civil protection and disaster relief as well as disaster medicine.

One tool created to provide medical support in case of largescale events is the German Medical Task Force (MTF). The MTF consists of several subunits located across Germany, which are supplied by different German relief organisations, e.g. the German Red Cross or the Malteser, and can be convened nationwide in the event of a disaster. These subunits are equipped with uniform medical gear and have to participate in special trainings for this task. But since the MTF system has been introduced lately, not all MTF subunits are fully operational yet. In order to train the subunits that have been already implemented, the BBK organised the civil protection exercise "Flinker Oktopus".

\subsection{Civil Protection Exercise "Flinker Oktopus"}

The exercise took place with around 440 participants (trainees, support staff, observers, press) on October 24-26, 2014, at the military training area Lehnin in Brandenburg. Eight different subunits of the MTF travelled up to $500 \mathrm{~km}$ with 32 vehicles to participate in the exercise and to practise for an emergency. The exercise scenario included an explosion in a fertilizer plant leading to deaths and injuries represented by volunteers. The trainees had to setup a treatment area and to organise patient transport and patient care under real conditions.

The exercise was intended to evaluate the management as well as the functionality and efficiency of the treatment area and its interfaces, as well as the teamwork of the participating subunits.

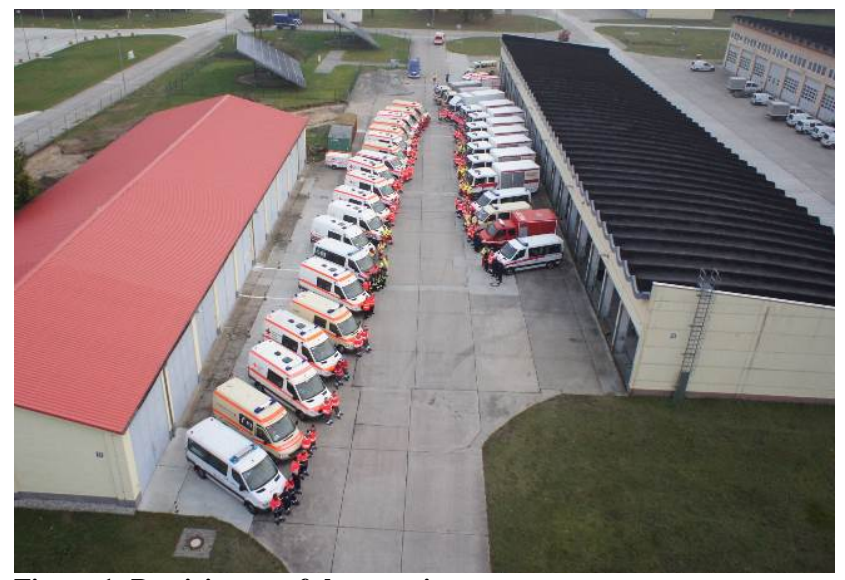

Figure 1: Participants of the exercise

\subsection{4k Camera System}

A very intuitive way of getting a quick overview of a disaster situation is to use optical satellite data or aerial imagery. But since the availability and spatial resolution of satellite data is still very restricted, aerial images have proved to be more sufficient for the provision of time-critical information (Joyce et al. 2009).

One key element during this exercise was the acquisition of aerial images using the $4 \mathrm{k}$ camera system on DLR's research helicopter BO 105 (see figure 2).

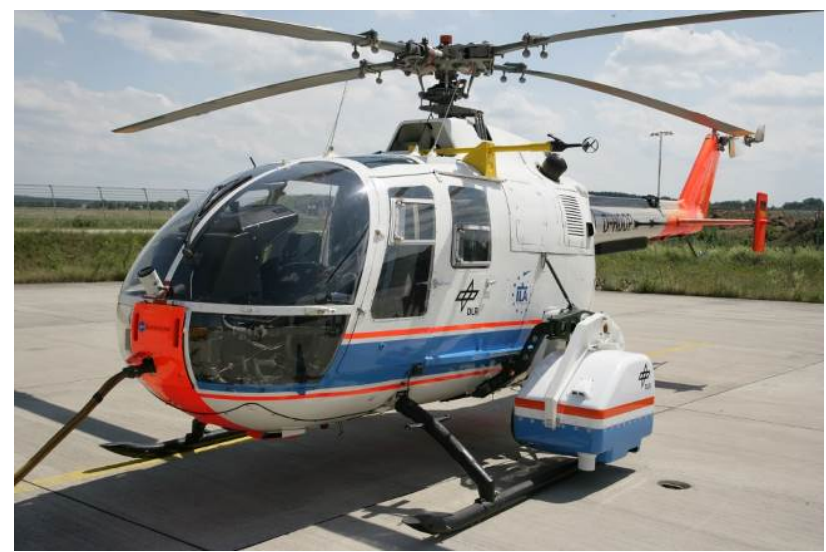

Figure 2: 4k camera system at DLR's research helicopter BO 105

The system consists of three non-metric off-the-shelf cameras, three high performance processing units for real-time processing of the data as well as precise GPS/IMU navigation system and a microwave data link including two antennas for data transfer rates of $11 \mathrm{Mbit} / \mathrm{s}$ (Kurz et al. 2014).

Table 1: Hardware components of the $4 \mathrm{k}$ camera system

\begin{tabular}{|c|c|c|c|c|}
\hline & Component & Size $[\mathrm{mm}]$ & Weight [kg] & Properties \\
\hline $2 \times$ & Microwave antenna $\left(\mathrm{SRS}^{1}{ }^{1}\right)$ & $120 \times 120 \times 113$ & $2 \times 0.75$ & \multirow{3}{*}{$\begin{array}{l}\text { Bidirectional C band data link } \\
\text { system with } 11 \text { Mbit/s eff. data } \\
\text { rate, for distances up to } 80 \mathrm{~km} \\
\text { line-of-sight. }\end{array}$} \\
\hline $1 \times$ & Network radio (SRS) & $58 \times 120 \times 230$ & 1.00 & \\
\hline $2 \times$ & Amplifier (SRS) & $78 \times 108 \times 220$ & $2 \times 1.60$ & \\
\hline $3 \times$ & Canon EOS ID X/C cameras & $158 \times 163.6 \times 82.7$ & $3 \times 1.34$ & \multirow[t]{2}{*}{ See table 2} \\
\hline $3 \times$ & \begin{tabular}{|l} 
Zeiss lenses \\
\end{tabular} & a72 length 65 & $3 \times 0.53$ & \\
\hline $1 \times$ & IMU (IGI ${ }^{2}$ Aerocontrol IId) & $200 \times 132 \times 137$ & 2.10 & \multirow{2}{*}{$\begin{array}{l}\text { Real-time GNSS/IMU measuring } \\
\text { and processing unit, RMS position } \\
0.1 \mathrm{~m} \text {. yaw } 0.05^{\circ} \text {, roll/pitch } 0.01^{\circ}\end{array}$} \\
\hline $1 \times$ & GPS/IMU processor (IGI) & $65 \times 140 \times 205$ & 1.80 & \\
\hline $1 \mathrm{x}$ & Camera trigger box & $190 \times 110 \times 60$ & 0.6 & $\begin{array}{l}\text { Raspberry } \mathrm{Pi}^{3} \text { minicomputer with } \\
\text { programmed trigger intervals }\end{array}$ \\
\hline $3 x$ & PC unit & $430 \times 310 \times 90$ & 8.5 & \\
\hline \multirow[t]{2}{*}{$1 \times$} & Housing + plattform ... & $542 \times 869 \times 595$ & 40.1 & $\begin{array}{l}\text { Carbon fiber hull, aluminum } \\
\text { structure }\end{array}$ \\
\hline & & & $\sum 81.4$ & \\
\hline
\end{tabular}

Table 1 lists the hardware components of the $4 \mathrm{k}$ camera system. The system is mounted on the external cargo carrier on the left side of the helicopter and is protected against vibrations by four additional absorbers. The system is connected to the helicopter's 25V/35A power supply as well as to its GPS antenna near the tail rotor and can be commanded from inside the helicopter via LAN or from the ground station via data link.

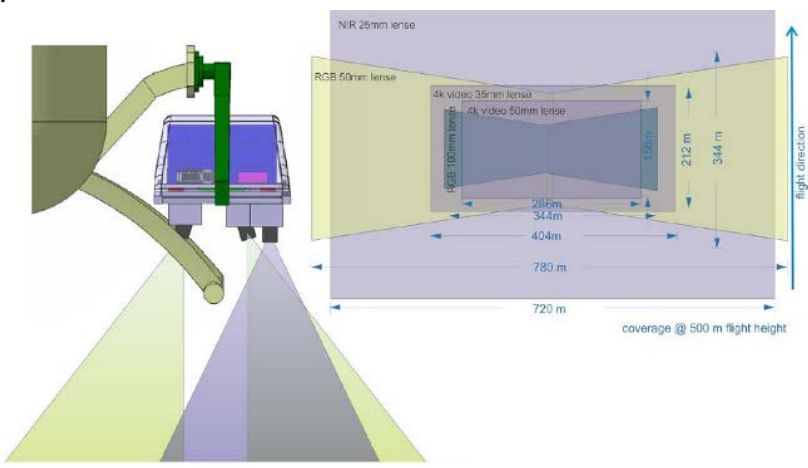

Figure 3: Field of view and coverages of the $4 \mathrm{k}$ camera system 
Table 2: Properties of the implemented CANON EOS cameras

\begin{tabular}{|c|c|c|}
\hline & Canon EOS $1 D-X$ & Canon EOS $1 D-C$ \\
\hline Lenses & $\begin{array}{l}\text { Zeiss Makro Planar 2/50, 2/100 } \\
\text { Zeiss Distagon } T^{*} 35\end{array}$ & $\begin{array}{l}\text { Zeiss Makro Planar 2/50, 2/100 } \\
\text { Zeiss Distagon T*35 }\end{array}$ \\
\hline Sensor / Pixel size & Full frame CMOS / 6.944 $\mu \mathrm{m}$ & Full frame CMOS / 6.944 $\mu \mathrm{m}$ \\
\hline Image size & $\begin{array}{l}5184 \times 3456 \text { pixel, ratio } 3: 2 \\
(17.9 \mathrm{MPix})\end{array}$ & $\begin{array}{l}5184 \times 3456 \text { pixel, ratio } 3: 2 \\
(17.9 \text { MPix) }\end{array}$ \\
\hline Image format & $\begin{array}{l}\text { JPEG (Canon L10-L1) } \\
\text { RAW (14Bit) }\end{array}$ & $\begin{array}{l}\text { JPEG (Canon L10-L1) } \\
\text { RAW (14Bit) }\end{array}$ \\
\hline $4 \mathrm{k}$ movies & & $\begin{array}{l}4096 \times 2160 \text { pixel, ratio } 1.9: 1 \\
8.85 \text { MPix } \\
\text { max. } 24 \text { fps / } 4: 2: 2 \text { YUV } 8 \text { bit } \\
1.7 \text { Gbps (uncompressed) } \\
0.5 \text { Gbps (MJPEG compressed) }\end{array}$ \\
\hline ISO & $100-204800$ & $100-204800$ \\
\hline $\begin{array}{l}\text { Max. frame rate/ } \\
\text { max. images }\end{array}$ & $14 \mathrm{fps} / 180$ images & $14 \mathrm{fps} / 180$ images \\
\hline Exposure time & $30 s-1 / 8000 s$ & $30 s-1 / 8000 s$ \\
\hline Data interface & LAN (EDSDK software interface) & LAN (EDSDK software interface) \\
\hline
\end{tabular}

With 542x869x595mm in width, length and height and a weight of $81.4 \mathrm{~kg}$, the $4 \mathrm{k}$ camera system is much smaller and lighter than the original 3K camera system and still comprises all possibilities for fast and effective image acquisition and processing as well as the option to acquire movies in $4 \mathrm{k}$ resolution.

Table 2 shows the properties of the CANON EOS cameras. Each camera has a different orientation allowing coverages of up to $2560 \times 460 \mathrm{~m}$ and resolutions of up to $3.5 \mathrm{~cm}$ depending on the implemented lenses and operation heights (see figure 2 and table 3).

Table 3: Field of view and coverages of aerial images acquired by the $4 k$ camera system depending on implemented lenses and operation height

\begin{tabular}{|c|c|c|c|c|c|c|}
\hline & $\begin{array}{l}\text { Wide area RGB } \\
50 \mathrm{~mm} \text { lense }\end{array}$ & $\begin{array}{c}\text { RGB } \\
\text { 50mm lense }\end{array}$ & $\begin{array}{c}\mathrm{RGB} \\
\text { 100mm lense }\end{array}$ & $\begin{array}{c}\text { NIR } \\
\text { 25mm lense }\end{array}$ & $\begin{array}{l}\text { 4k video } \\
35 \mathrm{~mm} \text { lense }\end{array}$ & $\begin{array}{c}4 \mathrm{k} \text { video } \\
50 \mathrm{~km} \text { lense }\end{array}$ \\
\hline $\begin{array}{l}\text { Viewing } \\
\text { directions }\end{array}$ & $\begin{array}{l}1 \times \text { Nadir } \\
2 \times \pm 32^{\circ}\end{array}$ & $2 \times \pm 19^{\circ}$ & $2 \times \pm 9^{\circ}$ & Nadir & Nadir & Nadir \\
\hline FOV & $\begin{array}{l} \pm 52^{\circ} \text { across, } \\
\pm 13^{\circ} \text { along }\end{array}$ & $\begin{array}{l} \pm 38^{\circ} \text { across } \\
\pm 13^{\circ} \text { along }\end{array}$ & $\begin{array}{l} \pm 19^{\circ} \text { across, } \\
\pm 7^{\circ} \text { along }\end{array}$ & $\begin{array}{l} \pm 36^{\circ} \text { across, } \\
\pm 26^{\circ} \text { along }\end{array}$ & $\begin{array}{l} \pm 22^{\circ} \text { across. } \\
\pm 12^{\circ} \text { along }\end{array}$ & $\begin{array}{l} \pm 16^{\circ} \text { across, } \\
\pm 9^{\circ} \text { along }\end{array}$ \\
\hline $\begin{array}{l}\text { Coverage/ } \\
\text { GSD@S500m }\end{array}$ & $\begin{array}{l}1280 \mathrm{~m} \times 230 \mathrm{~m} / \\
6.9 \mathrm{~cm} \text { nadir }\end{array}$ & $\begin{array}{c}780 \mathrm{~m} \times 230 \mathrm{~m} / \\
6.9 \mathrm{~cm} \text { nadir }\end{array}$ & $\begin{array}{c}344 \mathrm{~m} \times 122 \mathrm{~m} / \\
3.5 \mathrm{~cm} \text { nadir }\end{array}$ & $\begin{array}{l}720 \mathrm{~m} \times 480 \mathrm{~m} / \\
13.8 \mathrm{~cm} \text { nadir }\end{array}$ & $\begin{array}{c}404 \mathrm{~m} \times 212 \mathrm{~m} / \\
9.9 \mathrm{~cm} \text { nadir }\end{array}$ & $\begin{array}{c}286 \mathrm{~m} \times 158 \mathrm{~m} \\
6.9 \mathrm{~cm}\end{array}$ \\
\hline $\begin{array}{l}\text { Coverage / } \\
\text { GSD@1000m }\end{array}$ & $\begin{array}{c}2560 \mathrm{~m} \times 460 \mathrm{~m} / \\
13.8 \mathrm{~cm} \text { nadir }\end{array}$ & $\begin{array}{c}1560 \mathrm{~m} \times 460 \mathrm{~m} / \\
13.8 \mathrm{~cm} \text { nadir }\end{array}$ & $\begin{array}{c}688 \mathrm{~m} \times 244 \mathrm{~m} / \\
7.0 \mathrm{~cm} \text { nadir }\end{array}$ & $\begin{array}{c}1440 \mathrm{~m} \times 960 \mathrm{~m} / \\
27.6 \mathrm{~cm} \text { nadir }\end{array}$ & $\begin{array}{c}808 \mathrm{~m} \times 424 \mathrm{~m} / / \\
19.8 \mathrm{~cm} \text { nadir }\end{array}$ & $\begin{array}{c}572 \mathrm{~m} \times 316 \mathrm{~m} \\
13.8 \mathrm{~cm}\end{array}$ \\
\hline
\end{tabular}

\subsection{Workflow and Data Distribution}

Figure 4 shows the main workflow of the $4 \mathrm{k}$ camera system and its processing components. As soon as the images are acquired, they are georeferenced with real-time GPS/IMU data and orthorectified with a high resolution digital elevation model.

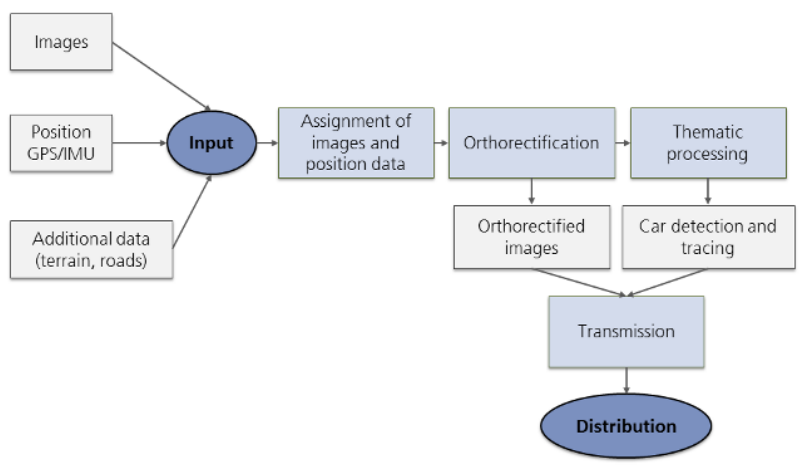

Figure 4: Workflow of the $4 \mathrm{k}$ camera system

In addition, an automatic algorithm detects cars on the images and computes their velocities. For this option the cameras acquire images in the so called burst-mode consisting of short sequences with a high framerate of up to three frames per second. The first picture of one boost is analysed with adaboost image classification using haar features (Viola and Jones 2004). For this step the processor has to be trained once in advance. To avoid false classifications and to optimise the results, the area to be classified gets limited to the road network (see figure 5).

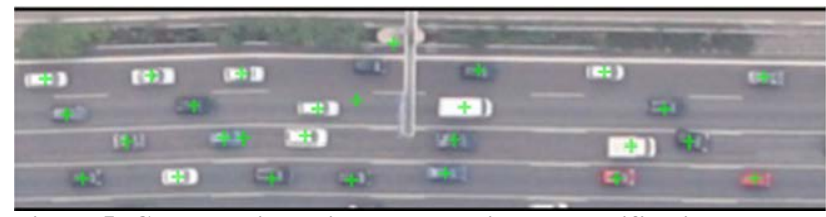

Figure 5: Car detection using adaboost image classification

After image classification an image subset is taken of each detected car and used as template. Now these templates get retrieved in the other images of the burst using a shape-based matching technique as shown in figure 6 (Steger et al. 2008).

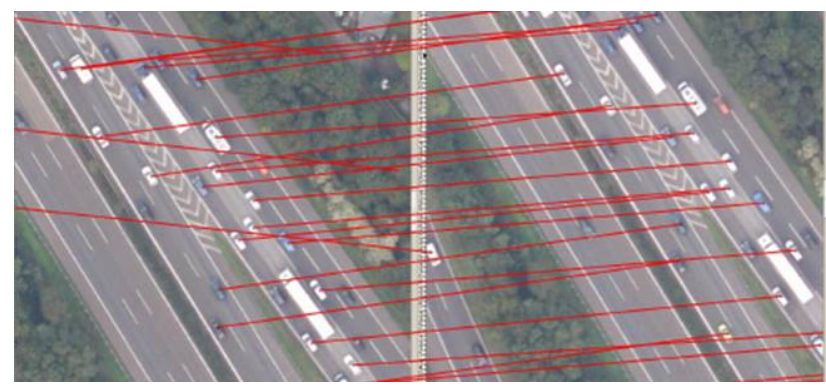

Figure 6: Tracking of cars using shape-based matching

One burst is followed by a short break of a few seconds until the aircraft has moved on and the cameras can cover a new area on the ground. Then the next burst is taken. The classification results get verified immediately using parameters, e.g. speed limits, from a database.

Following this, aerial images and derived traffic data consisting of positions, velocities and driving directions of the detected cars are transferred to a mobile ground station via microwave data transmission. On the ground the traffic data gets aggregated to road segments and additional information on traffic flow and density are derived.

Pre-processed image data and extracted traffic information are transmitted to a mobile ground station using a commercial autotracking microwave C-Band downlink. The ground station consists of a microwave ground antenna and data processing and validation infrastructure. If necessary, the station can be moved close to the disaster area. For this purpose, a tent for the crew and the technical infrastructure can be set up.

Once the images and traffic data are transmitted to the ground successfully, they get passed on to a server. This central backbone within the process chain is called traffic data platform (TDP), where all acquired raw data, extracted traffic data are centrally stored. It can be distinguished between a mobile TDP (mTDP) and a stationary TDP (sTDP) one. Whereas the mTDP is being used in the mobile ground station, the sTDP is centrally hosted at the DLR. If there is an internet connection available in the field, e.g., through satellite internet, the mTDP automatically synchronizes with the sTDP (Behrisch et al. 2009, Tcheumadjeu et al. 2012).

Further image data preparation steps include server-side tiling and pyramid calculation for the creation and delivery of Tile Map Service (TMS). The TMS can be provided either in Open Source Geospatial Foundation (OSGEO) as well as in Slippy Map standard in order to be consumable by a wide range of web-mapping clients. 
Another application provided by VABENE++ is the semiautomatic derivation of parking or assembly areas from aerial imagery (Kersten 2014; Römer et al. 2014). As a further development of the general workflow described in Römer et al. (2014), GIS-server and geodatabase are deployed in a virtual machine, which is locally hosted at the mTDP in order to fulfil the requirement to be independent from any internet connections. Occupancy information is ingested to an ESRI File Geodatabase and is provided as Representational State Transfer (REST) and Open Geospatial Consortium (OGC) - compliant Web Services (WMS/WFS).

In order to meet further decision support requirements, data from aerial and ground-based traffic monitoring can be visualised by the EmerT portal (Emergency mobility of rescue forces and regular traffic) shown in figure 7 . This web based decision support application was developed by DLR especially for traffic management and implies information on real-time traffic situation together with prognosis and traffic simulation (Bieker et al. 2012). Traffic simulations enable traffic state estimations and forecasts and can contribute to the identification of traffic bottlenecks. Traffic simulation of the EmerT tool is based on the open source traffic simulation package SUMO developed by DLR (Krajzewicz et al. 2012). In addition the tool provides travel times for rescue forces and allows Traffic Management Centers, Emergency Rescue Services, Police and Emergency Call Centres to exchange information.

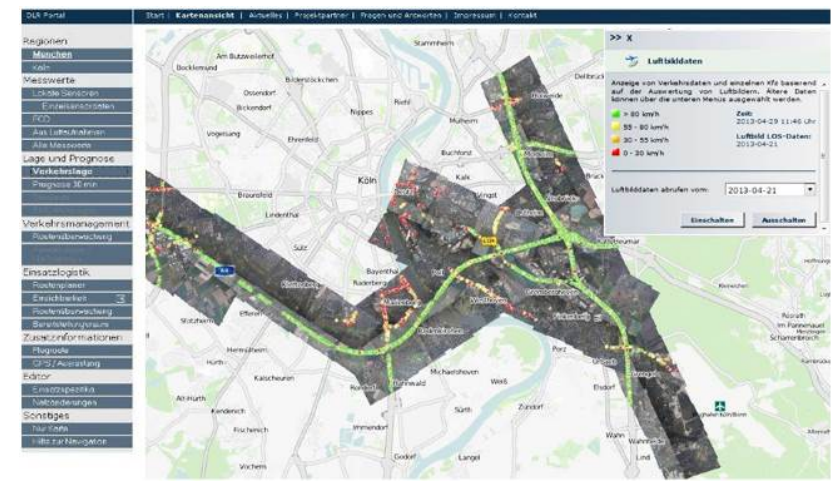

Figure 7: Visualisation of aerial imagery and traffic data using the EmerT web portal

End users have appreciated the various possibilities to visualise the results in near-real time, but one common requirement is still to be able to use individually selected printouts of the data. For this reason a new print service is under development enabling a user of a web-client to produce a high-quality and high-resolution (300 dpi) map product in various formats ondemand. The service is based on map templates, consumes several web services and allows for an automatic configuration of a map product, including the positioning and arrangement of map frame elements (e.g., legend, grids, map marginalia). The map configuration is straightforward using the current display extent and information layers selected by a web-client user. A first demonstrator of the print-service was successfully tested during the exercise in Lehnin and frequently requested by the exercise management team and visitor delegations. Experiences from the campaign showed that the first analogue map products were available 25 - 30 minutes after image data acquisition. If provided as OGC-compliant web-services, further information layer can be used for map creation, e.g., information on road traffic and parking occupancy as derived from aerial imagery and terrestrial cameras.

\subsection{On-Site Decision Support}

Geographic reference maps based on pre-event satellite imagery as well as aerial imagery provided by the Federal Agency for Cartography and Geodesy (BKG) were created in advance of the field exercise. The maps served as important training material and planning basis for the exercise organizing team. In addition to the imagery and basic reference information, the maps included also exercise specific and tactical information provided by the MTF in advance of the exercise, such as assembly and gathering areas as well as the treatment areas that were established during the exercise. All reference data sets were pre-processed, stored in a geodatabase and provided as web services.

During the exercise the VABENE++ mobile ground station was located in the same building as the coordination team of the exercise. This allowed a short way for communication and exchange of information.

At the beginning of the exercise one task was to monitor the approaching MTF subunits. To get detailed information about their recent positions, the MTF leaders of each subunit had received mobile phones from DLR with special software installed. This software transmitted the position of the mobile phones and allowed to display the vehicles' positions directly at the coordination point for arrival. Based on this information, the helicopter BO 105 was sent in the direction of the subunits in order to monitor their approach as well as the traffic situation on the way. This information could have been used to delegate the subunits to alternative routes in case of traffic disruption.

Once the exercise started, several different data sources were used. Small traffic cameras were installed at fixed positions to monitor movements of the vehicles as well as the development of the exercise in general. The images of these cameras were transmitted to the ground station via a locally installed mesh network and allowed to monitor the different exercise sites at the same time at the central coordination point. During the setup phase of the treatment area, the BO 105 was flying above the exercise area, monitoring the event with aerial images, acquired by the $4 \mathrm{k}$ camera system. The images were transmitted directly to the mobile ground station, where they were processed and supplied as web-services in order to be visualized in a webclient. Figure 8 shows the exercise area at the military training area Lehnin on a $4 \mathrm{k}$ aerial image. New patients were brought to the treatment area from the top right of the image and were admitted at the two white tents close to the roundabout. The treatment area can be seen as line of grey tents. Afterwards the patients were picked up again (large square on the bottom right) and brought to a simulated hospital.

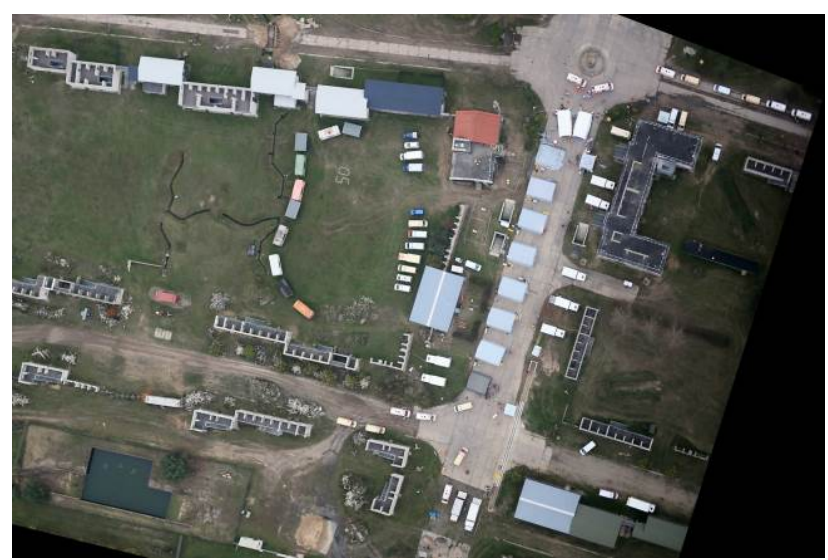

Figure 8: Aerial image acquired by the 4k camera system during the exercise 
In addition, up-to-date aerial image maps were created in the field and printed in DIN A3 and in a high graphic quality (300 dpi). Figure 9 shows a typical map product that was requested by the exercise coordination team. The map shows the treatment area which was currently set-up by the exercise participants as indicated by the rectangular grey and green tents. Aerial imagery acquired on 25 October afternoon with a spatial resolution of $20 \mathrm{~cm}$ served as map backdrop.

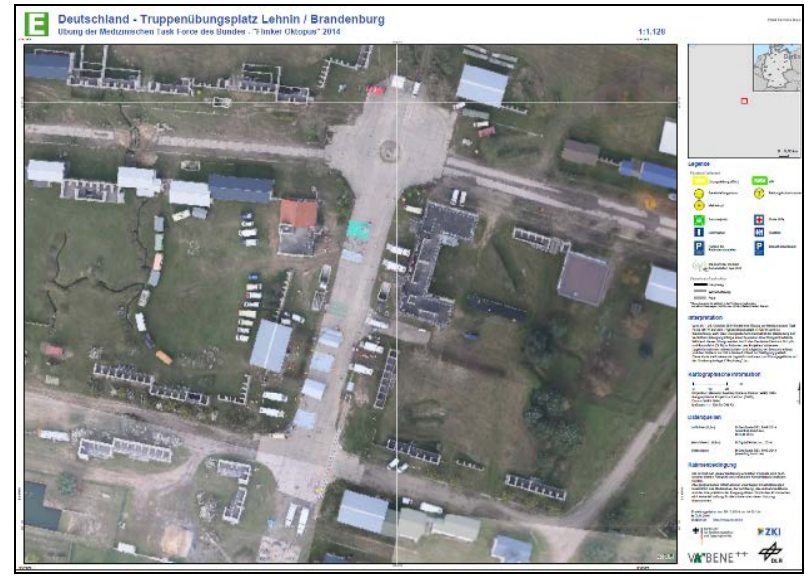

Figure 9: Map product created during the field exercise using the print service

Another viewing angle was provided by images taken by a small device called Micro Aerial Vehicle (MAV). It consists of an AscTec Falcon 8 flight system and a GoPro Hero3+ camera to acquire images and videos. This perspective allows the detailed evaluation of a situation and offers a good overview at the same time (see figure 10).

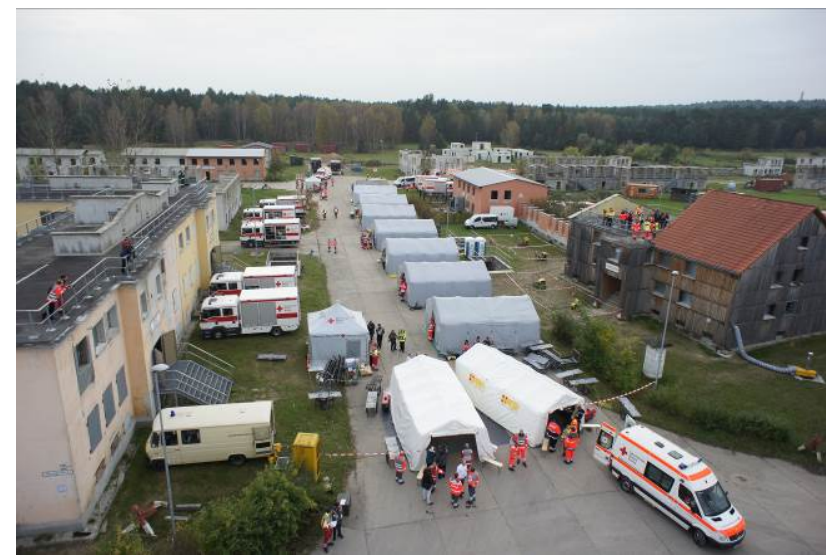

Figure 10: Image of the treatment area during the exercise acquired by a MAV

\section{CONCLUSION}

The VABENE++ system including image acquisition, automatic processing, data transfer, distribution and visualisation proved once again to work stable and reliable during field-tests.

By providing in-situ data from aerial and terrestrial camera systems together with derived evaluation products, VABENE++ offered valuable contributions for situation assessments to the coordination staff of the exercise. Especially the flexible deployment of the $4 \mathrm{k}$ camera system on the helicopter BO 105 allowed a fast realisation of user requirements when it came to covering specific or additional areas quickly during the exercise.
Experiences from the field exercise underpinned the usefulness of the client-based map production process and thus the need of further developments regarding the print service. These map elements (overview map, legend and map interpretation text) as well as the provision as well as the extension of further print templates.

Nevertheless, the provision of data always has to come along with very close communication with the persons this data is addressed to. Disaster management follows certain workflows and decision support systems have to be easy to understand, easy to handle and compatible to existing organisational workflows and possibly existing and already implemented software tools. This appears to be a great challenge, since the federal system in Germany does not provide standards when it comes to hardware or software tools to be used for disaster management. Particularly in terms of technical standards for data delivery, VABENE++ is facing this challenge by establishing OGC-compliant web-services that can be consumed by wide range of clients and software products.

During disasters all decision makers highly depend on reliable information for situation assessment and the tools developed in VABENE++ can contribute to this urgent need.

\section{REFERENCES}

Behrisch, M., Bonert, M., Hinkeldein, D., Krajzewicz, D., Kuhns, G., Wang, Y.-P., 2009: DELPHI - a joint web decision support application for real time traffic situation analysis and prognosis, information exchange and cooperation. In: ITS world congress 2009, 21-25 September 2009, Stockholm.

Bieker, L., Behrisch, M., Ruppe, S., 2012: EmerT - a web based decision support tool for Traffic Management. In: 19th ITS World Congress 2012, Vienna, Austria.

Joyce, K. E., Bellis, S. E., Samsonov, S. V., McNeill, S., J., Glassey, P. J., 2009: A review of the status of satellite remote sensing and image processing techniques for mapping natural hazards and disasters. In: Progress in Physical Geography 33(2) (2009) pp. 183-207.

Kersten, J., 2014: Simultaneous feature selection and Gaussian mixture model estimation for supervised classification problems. In: Pattern Recognition, 47, pp. 2582-2595.

Krajzewicz, D., Erdmann, J., Behrisch, M., Bieker, L., 2012: Recent Development and Applications of SUMO - Simulation of Urban MObility. In: International Journal on Advances in Systems and Measurements (5), 3\&4, pp. 128-138.

Kurz, F., Tuermer, S., Meynberg, O., Rosenbaum, D., Runge, H., Reinartz, P., 2012: Low-cost optical Camera System for real-time Mapping Applications. In: Photogrammetrie Fernerkundung Geoinformation 2012 (2), pp. 159-176.

Kurz, F., Rosenbaum, D., Meynberg, O., Mattyus, G., 2014: Real-time mapping from a helicopter with a new optical sensor system. In: Gemeinsame Tagung 2014 der DGfK, der DGPF, der GfGI und des GiN (DGPF 23/2014), Hamburg, Germany.

Römer, H., Kersten, J., Kiefl, R., Plattner, S., Mager, A., Voigt, S., 2014: Airborne near-real-time monitoring of assembly and parking areas in case of large-scale public events and natural disasters. In: International Journal of Geographical Information Science, 28(4), pp. 682-699. 
Steger, C., Ullrich, M., Wiedemann, C., 2008: Machine vision algorithms and applications. WILEY VCH Verlag GmbH und Co. KGaA, chapter 3.

Tcheumadjeu, L.C., et al., 2012. EmerT - supporting traffic parameter estimation from low cost and low resolution uncalibrated web cameras. In: 19th ITS world congress, 22-26 October 2012, Vienna.

Viola, P., Jones, M.J., 2004: Robust Real-Time Face Detection. In: International Journal of Computer Vision, 57, pp.137-154. 